\title{
Precautions used by occupational health nursing students during clinical placements
}

\author{
Prof TMM Maja, PhD \\ Associate Professor, Faculty of Science, Tswane University of Technology \\ MJ Motshudi, M Sc Nursing \\ Lecturer, Adelaide Tambo School of Nursing, Tshwane University of Technology
}

\section{Kev words}

Universal precautions, high risk patients, micro-organisms, human immunodeficiency virus, occupational health nursing students.

\section{Correspondence address}

TMM Maja (PhD)

Associate Dean Faculty of Science

Tswane University of Technology

\section{Abstract: Curationis 32 (1): 14-19}

Protection of health care workers including students from being infected when caring for high risk patients is a major cause for concern to all promoting occupational health. Safety of every employee is mandatory. Furthermore, universal guidelines for precautions must be used by all interacting with high risk patients and clients to protect themselves and prevent the spread of infection.

The aim of this paper was to ascertain the availability of universal guidelines for precautions against the spread of infection in clinical settings and determine the precautions used by OHN students during their clinical placements. To realise these objectives, a quantitative and descriptive design was followed. A purposive sampling method was used to select 45 Occupational health nursing students who participated in the study.

Data was collected with the use of a structured questionnaire and the results revealed that: most units where OHN students were placed for clinical experience had guidelines for universal precautions although these were not always accessible to them; regarding compliance to universal precautions, OHN students were reportedly aware of the hazards of failure to comply although in some emergencies and where personal protective material was not available, they had to provide care without using protective equipments. Recommendations made include that employers and staff at all occupational settings must ensure that updated guidelines for universal precautions are available and accessible to every body interacting with high risk patients; health care providers and students must be fully informed about and should always adhere to universal precautions.

Tel : (012) 382-6229

Fax :(012) 382-9378

Email:majatmm@tut.ac.za 


\section{Introduction}

Health care providers exposed to high risk patients, blood and bloody fluids are particularly vulnerable to the threat of being infected with blood borne viruses and human immunodeficiency virus (HIV), hepatitis B and hepatitis C if universal precautions are not adhered to consistently whilst caring for these patients. These emerging infectious diseases have generated anxicties, fears and challenges to health care providers including students who may be exposed to high risk patients during clinical training. As part of their daily interventions, health care providers handle needles, syringes, sharps and have to administer injections to patients suffering from different types of ailments. Safe practices in handling injections are crucial to prevent accidental needle pricks which may result in infecting self or other patients. Estimates are that annually, unsafe injections account for a proportion of $(39 \%)$ new hepatitis B and $(40 \%)$ hepatitis C infections and (5\%) new HIV infections (WHO, 2003).

Employers and staff responsible for clinical settings must be fully informed about universal precautions to be taken by all interacting with patients and clients/employees to ensure safe and conducive environments for working and learning. In terms of the Occupational Health and Safety Act 85 of 1993, "every employer shall provide and maintain a working environment that is safe and without risks to the health of employees" (South Africa, 1993:12). Most employers regard hazards and risks to health as relating to safety, noise, chemicals, heat and dust and do not often identify risks caused by infections.

In the 1980s, the Centres for Disease Control and Prevention (CDC), USA, published guidelines urging the use of "universal precautions" based on amongst others, that health care workers could not promptly identify most patients infected with contagious diseases at initial presentation and therefore do not take precautions when providing care to patients (CDC, 2001:6). In South Africa, it has been estimated that 5.54 million people have been infected with HIV, while almost $50 \%$ of all deaths are attributed to HIV/AIDS (Sta- tistics South Africa, 2007: 12). Prevention of HIV and AIDS is therefore the first priority area as reflected in the HIV/ AIDS and STD Strategic Plan for South Africa 2002-2005 (National Department of Health, 2000:15). Health care providers are also urged to comply with the safety rules embedded in universal precautions at all times when caring for high risk patients.

Students enrolled for Occupational health nursing are expected to have practical exposure in occupational settings suitable for creating learning opportunitics, in addition to the theory offered in the classroom. The purpose of creating learning opportunities is to prepare the student to function effectively in this speciality and to be skilled in ethical decision making and moral reasoning by the end of the programme (South African Nursing Council, 1993: 23). It has been argued that nursing is a practice discipline and the importance of clinical learning cannot be over emphasized. Research indicates that clinical learning provides opportunities to apply theory to practice and foster problem-solving and decision-making skills, collaboration with others and development of legal and ethical morals (Chabeli, 1999: 22; Maja, Van Niekerk \& Van Dyk, 1997: 2; Masarweh, 1999:44).

\section{Problem Statement}

Emerging infectious diseases such as blood borne viruses and human immunodeficiency virus (HIV) in recent years have created new challenges for all health care providers, including students who may be interacting with infected patients and clients during their clinical exposure. Microbes transmitted by airborne, droplet or contact routes often generate anxieties and fears of being infected among $\mathrm{OHN}$ students, particularly when placed in units having high risk patients/clients. All patients need quality care and equal treatment from health care providers, including students. In line with their requirements for training, $\mathrm{OHN}$ students must be exposed to relevant occupational settings for practical experience so as to be competent by the time they complete their studies. The concern, however, is that during their placement in occupational settings, OHN students are also exposed to the risk of being infected if universal precautions are not complied with when interacting with high risk patients. No studies were found that explored precautions used by students exposed to high risk patients during clinical placements.

\section{Operational definitions}

The following terms are used to convey the meanings of the main concepts in this paper:

\section{- Infection}

Infection refers to the transfer of discase causing organisms from one person to another or inanimate objects, or orthopod vector to a human being (Zulu \& Chalandra, 2001:46).

\section{- High risk patients}

In this study, high risk patients or clients refer to those infected with HIV, hepatitis $B$, and hepatitis $C$ and other related infectious diseases.

\section{- Occupational health nursing student}

An Occupational health nursing student is a registered nurse who is enrolled to advance studies in Occupational Health Nursing at a tertiary education institution.

\section{- Occupational settings}

For the purpose of this study, occupational settings refer to industries, hospital wards or units, clinics/health care centres and any other work setting. Occupational settings may be used for clinical teaching and learning.

\section{- Clinical practica}

Clinical practica involves clinical learning opportunities in health care settings under the supervision of the registered nurse or registered midwife, and where appropriate, other knowledgeable and skilled persons (South African Nursing Council, 1994:5)

\section{Purpose and Objectives of the study}

The purpose of this study was to determine the availability of guidelines for universal precautions used in occupational heath settings and describe precautionary measures used by OHN students in protecting themselves and other patients against being infected. 
The following objectives were set to achieve the purpose of the study:

- Ascertain the availability of guidelines for universal precautions in occupational health settings.

- Identify and describe precautionary measures taken by $\mathrm{OHN}$ students in efforts to minimize the risk of being infected and spreading infection during clini cal practica.

\section{Research Design and Methods}

The study utilized a quantitative and descriptive design. Quantitative approach allows the researcher to analyze data using numerical information through statistical procedures (Polit, Beck \& Hungler, 2001:472). A descriptive design aims at obtaining complete and accurate information through observation, in order to provide a picture of the situation as it naturally happens. The descriptive design is also used to identify problems within current practice (Burns \& Grove, 2003:252).

\section{Sample and procedure}

A purposive sample was used to select $45 \mathrm{OHN}$ students for this study. Purposive sampling is based entirely on the judgement of the researcher in that the sample is composed of elements that contain the most characteristic, representative or typical attributes of the population (Singleton et al., 1988:153 in De Vos, Strydom, Fouche \& Delport, 2004: 207). The sampling frame was obtained from two groups of OHN students who were registered at Tshwane University of Technology at the time of data collection. Selection criteria for inclusion in the study were:

- OHN students registered at

Tshwane University of Technology who were exposed to selected occupational clinical settings for practical experience during their final year of Post Basic training;

- $\quad$ Either male or female;

- Voluntary participation.

\section{Data Collection}

The study employed a structured questionnaire with closed and open ended

Table 1: Units where OHN students were placed for clinical experience

\begin{tabular}{|l|l|}
\hline UNIT & NUMBER \\
\hline Emergency/trauma & 12 \\
\hline Medical & 10 \\
\hline Occupational health centre in mining industries & 16 \\
\hline Wellness and VCT & 7 \\
\hline TOTAL & 45 \\
\hline
\end{tabular}

questions for data collection. The instrument included a section on demographic data and questions which focused on availability of guidelines for universal precautions, preventative measures used by OHN students during their placement in selected clinical settings and compliance with universal precautions. The researchers distributed the questionnaires to eligible participants and these were collected after completion.

\section{Validity and reliability}

An expert in the field of occupational health nursing assessed the questionnaire for content validity and recommended that additional qualifications should be added in the biographic data of participants. These were included in the questionnaire and content validity was further enhanced by including a variety of questions based on information gathered during literature review. A pilot study was conducted with five OHN students who met the set criteria to pre-test the reliability of the research instrument. No flaws were detected as all participants interpreted questions as anticipated and the results tallied with the final findings of the study.

\section{Data Analysis}

Quantitative data was analysed using SPSS version 11.5 and Microsoft Excel. Descriptive and inferential statistics were employed to describe the findings. The responses to open-ended questions were analysed by the researcher through content analysis.

\section{Ethical Considerations}

Ethical issues specific to this research were considered (Democratic Nurses' Organization of South Africa, 1998: 2.3.2-2.3.4; Burns \& Grove, 2003:94). These entail ensuring anonymity and confidentiality of participants; obtaining informed consent from participants, voluntary participation and informing participants of their right to withdraw from the study at any time they so wished without victimization.

\section{Results and Discussion}

\section{Biographic data}

Forty five OHN students participated in the study. Their ages ranged from 30 to 45 years with a mean age of 38 years. All were registered nurses mostly having additional qualifications such as Diploma Operating Theatre, Paediatric Nursing, Advanced Community and Psychiatric Nursing. Participants were allocated to wards/units for clinical experience during their training as reflected in Table 1 .

\section{Availability of universal guidelines for precautions}

As reflected in Table 2, most participants $35(77,7 \%)$ acknowledged that the units where they were placed for occupational clinical experience had guidelines for universal precautions against occupational infections, 7 $(22,2 \%)$ participants reported that the units where they were allocated did not have the guidelines and $3(6,6 \%)$ were unsure. Of those who reported that the units had guidelines, $28(62,2 \%)$ added that these were mainly kept in the sister-in-charge's room and were not always accessible when needed. Although staff in units where guidelines were accessible should be commended, it is important that these guidelines must always be made available to all health care providers interacting with patients. Having these universal precautions guidelines available and accessible to all, will allow health care providers, including students to refer and clarify issues without depending 


\begin{tabular}{|l|l|l|}
\hline Compliance with precautionary measures & Frequency & Percentage \\
\hline $\begin{array}{l}\text { Washing of hands with soap and water after working with a patient and before } \\
\text { starting with another. }\end{array}$ & 40 & 88,9 \\
\hline Wearing protective clothing during handling of body fluids and infected material. & 37 & 82,2 \\
\hline Availability of personal protective equipment & 35 & 77,8 \\
\hline All re-usable instruments should be decontaminated and sterilized & 40 & 88,9 \\
\hline Education and training on preventive measures & 43 & 95,5 \\
\hline $\begin{array}{l}\text { Covering of any sores or cuts and avoiding HIV infected patients with weeping } \\
\text { dermatitis }\end{array}$ & 38 & 84,4 \\
\hline Avoiding needle stick injury through appropriate precautions & 45 & 100 \\
\hline Availability of post-exposure prophylaxis & 40 & 88,9 \\
\hline Adapted from Centres for disease and Control, 2001. & & \\
\hline
\end{tabular}

on mentors or supervisors who may not always be available for teaching. The Occupational Health and Safety Act No 85 of 1993, refer to the importance of providing such information, instructions, training and supervision as may be necessary and as far as is reasonably practicable, to ensure the health and safety of employees (South Africa, 1993:14)

\section{Washing of hands with soap and water}

With regard to washing of hands, 40 $(88,9 \%)$ reported that they washed hands with soap and water after working with a patient and before attending to another. Washing of hands with soap and water before and after attending to patients is crucial in protecting not only the health care provider but also preventing the spread of micro-organisms to other patients by direct contact. Hands are the parts of the body which most often comes into direct contact with contaminated objects and that the single most important measure to prevent the spread of micro-organisms by direct contact, is therefore to wash hands regularly (Uys, 1999:248).

\section{Wearing of personal protective equipments}

Personal protective equipments (PPEs) include gloves, masks, gowns, boots and head coverings to protect care providers from being infected with microorganisms. A total of $37(82,2 \%)$ participants indicated that they wore protective clothing during handling of body fluids and infected material, whilst $8(17,8 \%)$ failed to wear PPEs due to lack of stock. The fact that some PPEs were not available to OHN students, indicate the lack of commitment from staff in units to control infections. As part of creating a safe and learning environment for all in clinical settings, the necessary equipments must be ordered in time and made accessible to all interacting with patients/clients. Knight and Bodsworth (1999:747) as well as Ncama and Uys (2001: 14) urge staff in charge of units to ensure that protective material is always made available to those who deal with blood and body fluids.

\section{Decontamination and sterilization of re-usable material}

Referring to decontamination and sterilization of re-usable material, most participants, $40(88,9 \%)$ reported to have complied with this precautionary measure. What was worrisome was that 5 $(11,11 \%)$ who did not comply, might have used syringes and needles with- out sterilization with detrimental effects to the patients/clients, including accidental needle sticks to health care providers. Studies regarding injection practices, estimate that $35 \%$ of all hepatitis $\mathrm{B}$ and the majority of hepatitis $\mathrm{C}$ cases are due to re-use of single use or nonsterilised and non-sterilisable equipment. Further reports indicate that about $20 \%$ of injections are unsafe in the African region (Millogo, 2003: 40; World Health Organization, 2003)

\section{Education and training of $\mathrm{OHN}$ students regarding precautions}

The majority of OHN students, 43 $(95,5 \%)$ affirmed that they had received education and training regarding protective measures to be taken when caring for high risk patients, whilst only 2 $(4,4 \%)$ seemed not to have been informed in this regard. During their training and prior to being exposed in clinical settings, OHN students should be fully informed about the importance of always complying with universal precautions and the consequences of failure to comply. Employers and staff in wards/units used for training of students must also be updated about developments in infection control and safety through workshops, conferences and in-service lectures (Rapparini, 2006:237; South Africa, 1993:14). 


\section{Covering of any sores or cuts from patients}

Open sores and cuts from the health care provider or patient may be sources of microbes which could be transmitted either way. Most participants 38 $(84,4 \%)$ indicated that they covered any sores or cuts from patients. Responding to other methods used to prevent the spread of infection when caring for wounds, participants indicated that they used the aseptic technique to promote healing and prevent complications. South Africa continues to have the largest number of people living with HIV/AIDS in the world with AIDS being one of the ten leading causes of death in 2005 (Statistics South Africa, 2007:19). With the growing numbers of people infected with HIV in South Africa, the importance of adhering to proper techniques in wound care must be considered. Tarantola, Dominique and Rachline (2006: 369) add that the realization of the risks linked with exposure to blood and bloody fluids in hospitals only became widespread with the advent of HIV and AIDS.

\section{Avoidance of needle stick injuries}

It became apparent from this study that $\mathrm{OHN}$ students were more vigilant about prevention of accidental needle stick pricks as all $45(100.0 \%)$ complied with this universal precaution. Participants reportedly used needles for injections more often in their patient care and thus felt the need to be more cautious when handling syringes and needles. Ncama and Uys (2001:14) reported that nurses who participated in their study acknowledged that "although they treated everybody as HIV positive, they were worried that they could not always avoid needle stick injuries." The authors suggest that more_technologically advanced universal precautionary instruments should be made available and accessible to those who handle body fluids and blood, such as the availability of magnets to pick up dropped sharps and puncture-resistant sharps containers (Ncama \& Uys, 2001: 17).

\section{Post exposure prophylaxis}

A total number of $40(88,9 \%)$ OHN students confirmed the availability of post exposure prophylaxis in units where they were exposed for practica. A fur- ther question in this regard inquired whether participants had any accidental needle sticks during their clinical practica. Although all OHN students stated that they were vigilant about prevention of accidental needle stick pricks, $43(95,5 \%)$ reported that they did not have any, whilst $2(6,7 \%)$ did not respond to the question. This implies that despite taking precautionary measures, OHN students are still vulnerable to accidental needle stick pricks. Asked if they used post exposure prophylaxis (PEP), 42 (93,3\%) participants responded that they had not used PEP, probably because they did not have accidental needle sticks or did not just use it. Less than half the number of $20(44,4 \%)$ OHN students had heard of staff members who had accidental needle stick pricks and had subsequently used PEP. These findings suggest that accidental needle stick pricks are not uncommon in occupational settings and that every body exposed must comply with precautions to prevent risks. In view of this, Makhubela-Nkondo (2007:21) reminds all health care providers and prospective constituencies to use available services such as voluntary confidential counseling and testing, annual physical assessments, referrals, liaison with other agencies that offer antiretroviral therapy and post-exposure prophylaxis to curtail any occupational hazards related to splashes or needle stick pricks.

\section{Limitations of the study}

The study sample_comprised OHN students from only one tertiary institution in Gauteng province. Although occupational clinical settings selected were also used by students from other institutions, these findings may not be generalized to other tertiary education institutions due to the small sample size $\mathrm{n}=45$ used for this study.

\section{Conclusion and \\ recommendations}

The results revealed that OHN students had information about prevention of health risks and had evidently applied this theory in clinical settings during their placements. Guidelines for universal precautions were reportedly available in most units, although $\mathrm{OHN}$ students reported inaccessibility of these in some units. In units where PPEs were not available when needed, OHN students had to risk interacting with patients and clients without protection.

\section{Recommendations}

- Employers and staff at all occupational settings must ensure that updated guidelines for universal precautions are available and accessible to every body interacting with high risk patients and clients.

- $\quad$ Health care providers and all students must be fully informed about and always adhere to universal precautions when interacting with patient/clients.

- $\quad$ Reporting promptly and compliance with PEP in the event of accidental needle stick injuries.

- $\quad$ PPEs must always be available and accessible for use by all interacting with high risk patients/ clients to ensure that precautions are adhered to at all times.

\section{References}

BODKIN, C \& BRUCE, J 2003: Health professionals' knowledge of prevention strategies following subcutaneous injury. Curationis. 26(4):22-28.

BURNS, N \& GROVE, SK 2003: The practice of Nursing Research. Conduct, Critique and Utilization: fourth edition. Philadelphia: WB Saunders.

CENTRES FOR DISEASE CONTROL. 2001: Preventing Occupational HIV Transmission to Healthcare Personnel. Available at http:// www.cdc.gov/hiv/pubs/facts/ hcwprev.htm.

CHABELI, M 1999: Student nurses learning needs and expectations in the clinical learning units. Curationis, 22 (4): 2428 .

DEMOCRATICNURSINGORGANIZATION OF SOUTH AFRICA 1998: Ethical standards for nurse researchers, Pretoria: DENOSA.

DE VOS, AS; STRYDOM, CB, FOUCHE, CB \& DELPORT,CSL 2003: Research at grassroots for Social Sciences Profession. $2^{\text {nd }}$ Edition. Van 
KNIGHT, VM \& BODSWORTH, NJ 1998: Perceptions and practice of universal blood and body fluid precautions by registered nurses at a Sydncy teaching hospital. Journal of Advanced Nursing. 27(4):746-751.

MAJA, TMM; VAN NIEKERK, SE \& VAN WYK, NC 1997: Clinical learning opportunities as experienced by PostBasic Community Health Nursing at tertiary education institutions. M Cur Dissertation, university of Pretoria.

MAKHUBELA-NKONDO, 0 2007: Universal precautions curtail occupational risk. Nursing Update. 31(1): 21.

MASSARWEH, LJ 1999: Promoting a positive clinical experience. $\underline{\text { Nurse }}$ Educator, 24 (3): 44-47.

MILLOGO, J 2003: The incidence of unsafe injections in Africa. Nursing Update. $40-41$.

NATIONAL DEPARTMENT OF HEALTH 2000-2005: HIV/AIDS and STD Strategic Plan for South Africa. Pretoria: Government Printers.

NCAMA, BP \& UYS, LR 2001: Exploring the fear of contracting HIV/AIDS among nurses in the province of KwaZulu Natal. Curationis. 26(2): 11-15.

POLIT, DF; BECK, CT \& HUNGLER, BP 2004: Essentials of Nursing Research: Methods Appraisals and utilizations. $7^{\text {th }}$ Edition. Philadelphia. Lippincot.

RAPPARINI, C 2006: Occupational HIV infection among health care workers exposed to blood fluids in Brazil. American Journal of Infection Control. 34(4):237-240.

STATISTICS SOUTH AFRICA 2007: Mortality and causes of death in South Africa, 2005. Findings from death notification. http://www.stassa.gov.za/ p l u b l l i c c a P030932005.pdf.(Accessed on 26 April 2008).

SOUTH AFRICAN NURSINGCOUNCIL 1994: Terminology List. First Edition. Pretoria.
CIL 1993: Teaching guide for a course in Clinical Nursing Science leading to registration of an additional qualification, Occupational Nursing Science R212. Pretoria.

SOUTH AFRICA 1993: Occupational Health and Safety Act No 85 of 1993. Government Gazettc. Pretoria.

TARANTOLA,A; ABITEBOUL, D \& RACHLINE, A 2006: Infection risks following accidental exposure to blood or body fluids in health care workers: A review of pathogens transmitted in published cases. American Journal of Infection control, 34 (6): 367-375.

UYS, L 1999: Fundamental Nursing. Cape Town: Maskew Miller.

WORLDHEALTHORGANIZATION. 2003: Technical Report. WHO, Geneva.

ZULU, M \& CHALANDRA, M 2001: Investigation of infection prevention and control in selected Malawian hospitals. Africa Journal of Nursing and midwiferv. 3(1): 46-50. 